\title{
Upwelling and isolation in oxygen-depleted anticyclonic modewater eddies and implications for nitrate cycling
}

\author{
Johannes Karstensen ${ }^{1}$, Florian Schütte ${ }^{1}$, Alice Pietri ${ }^{2}$, Gerd Krahmann ${ }^{1}$, Björn Fiedler ${ }^{1}$, Damian Grundle ${ }^{1}$, \\ Helena Hauss $^{1}$, Arne Körtzinger ${ }^{1,3}$, Carolin R. Löscher ${ }^{1, a}$, Pierre Testor ${ }^{2}$, Nuno Vieira ${ }^{4}$, and Martin Visbeck ${ }^{1,3}$ \\ ${ }^{1}$ GEOMAR, Helmholtz Zentrum für Ozeanforschung Kiel, Düsternbrooker Weg 20, 24105 Kiel, Germany \\ ${ }^{2}$ Sorbonne Universites (UPMC Univ. Pierre et Marie Curie, Paris 06)-CNRS-IRD-MNHN, UMR 7159, \\ Laboratoire d'Oceanographie et de Climatologie (LOCEAN), Institut Pierre Simon Laplace (IPSL), \\ Observatoire Ecce Terra, 4 place Jussieu, 75005 Paris, France \\ ${ }^{3}$ Kiel University, Kiel, Germany \\ ${ }^{4}$ Instituto Nacional de Desenvolvimento das Pescas (INDP), Cova de Inglesa, Mindelo, São Vicente, Cabo Verde \\ ${ }^{a}$ now at: Nordic Center for Earth Evolution, University of Southern Denmark, Campusvej 555230 Odense M, Denmark
}

Correspondence to: Johannes Karstensen (jkarstensen@ geomar.de)

Received: 28 February 2016 - Discussion started: 11 March 2016

Revised: 7 March 2017 - Accepted: 31 March 2017 - Published: 27 April 2017

\begin{abstract}
The temporal evolution of the physical and biogeochemical structure of an oxygen-depleted anticyclonic modewater eddy is investigated over a 2-month period using high-resolution glider and ship data. A weakly stratified eddy core (squared buoyancy frequency $N^{2} \sim 0.1 \times 10^{-4} \mathrm{~s}^{-2}$ ) at shallow depth is identified with a horizontal extent of about $70 \mathrm{~km}$ and bounded by maxima in $N^{2}$. The upper $N^{2}$ maximum $\left(3-5 \times 10^{-4} \mathrm{~s}^{-2}\right)$ coincides with the mixed layer base and the lower $N^{2}$ maximum $\left(0.4 \times 10^{-4} \mathrm{~s}^{-2}\right)$ is found at about $200 \mathrm{~m}$ depth in the eddy centre. The eddy core shows a constant slope in temperature/salinity $(T / S)$ characteristic over the 2 months, but an erosion of the core progressively narrows down the $T / S$ range. The eddy minimal oxygen concentrations decreased by about $5 \mu \mathrm{mol} \mathrm{kg}{ }^{-1}$ in 2 months, confirming earlier estimates of oxygen consumption rates in these eddies.

Separating the mesoscale and perturbation flow components reveals oscillating velocity finestructure $\left(\sim 0.1 \mathrm{~m} \mathrm{~s}^{-1}\right)$ underneath the eddy and at its flanks. The velocity finestructure is organized in layers that align with layers in properties (salinity, temperature) but mostly cross through surfaces of constant density. The largest magnitude in velocity finestructure is seen between the surface and $140 \mathrm{~m}$ just outside the maximum mesoscale flow but also in a layer underneath the eddy centre, between 250 and $450 \mathrm{~m}$. For both regions a cyclonic rotation of the velocity finestructure with depth sug-
\end{abstract}

gests the vertical propagation of near-inertial wave (NIW) energy. Modification of the planetary vorticity by anticyclonic (eddy core) and cyclonic (eddy periphery) relative vorticity is most likely impacting the NIW energy propagation. Below the low oxygen core salt-finger type double diffusive layers are found that align with the velocity finestructure.

Apparent oxygen utilization (AOU) versus dissolved inorganic nitrate $\left(\mathrm{NO}_{3}^{-}\right)$ratios are about twice as high (16) in the eddy core compared to surrounding waters (8.1). A large $\mathrm{NO}_{3}^{-}$deficit of 4 to $6 \mu \mathrm{mol} \mathrm{kg}{ }^{-1}$ is determined, rendering denitrification an unlikely explanation. Here it is hypothesized that the differences in local recycling of nitrogen and oxygen, as a result of the eddy dynamics, cause the shift in the AOU : $\mathrm{NO}_{3}^{-}$ratio. High $\mathrm{NO}_{3}^{-}$and low oxygen waters are eroded by mixing from the eddy core and entrain into the mixed layer. The nitrogen is reintroduced into the core by gravitational settling of particulate matter out of the euphotic zone. The low oxygen water equilibrates in the mixed layer by air-sea gas exchange and does not participate in the gravitational sinking. Finally we propose a mesoscalesubmesoscale interaction concept where wind energy, mediated via NIWs, drives nutrient supply to the euphotic zone and drives extraordinary blooms in anticyclonic mode-water eddies. 


\section{Introduction}

Eddies are associated with a wide spectrum of dynamical processes operating on mesoscale (order $100 \mathrm{~km}$ ) and submesoscale (order of 0.1 to $10 \mathrm{~km}$ ) horizontal scales, but also down to the molecular scale of three-dimensional turbulence (McWilliams, 2016). The interaction of these processes creates transport patterns in and around eddies that provoke often very intense biogeochemical and biological feedback such as plankton blooms (Lévy et al., 2012; Chelton et al., 2011).

The simplest way of classifying eddies is by their sense of rotation into cyclonic-rotating and anticyclonic-rotating eddies (e.g. Chelton et al., 2011; Zhang et al., 2013). However, when considering the vertical stratification of eddies, a third group emerges that shows in a certain depth range a downward displacement of isopycnals towards the eddy centre, as observed in anticyclonic eddies (ACEs), but an upward displacement of isopycnals in a depth range above, as observed in cyclonic eddies (CEs). Because the depth interval between upward and downward displaced isopycnals creates a volume of homogenous properties, called a "mode", such hybrid eddies have been called anticyclonic modewater eddies (ACMEs) or intra-thermocline eddies (McWilliams, 1985; D'Asaro, 1988; Kostianoy and Belkin, 1989; Thomas, 2008). Modewater eddies occur not only in the thermocline, but also in the deep ocean, like for example Mediterranean Outflow lenses (Meddies) in the North Atlantic (Armi and Zenk, 1984) or those associated with deep convection processes (e.g. the Mediterranean Sea, Testor and Gascard, 2006). Schütte et al. (2016a, b) studied eddy occurrence in the thermocline of the tropical eastern North Atlantic considering CEs, ACEs, and ACMEs. They estimated that about $9 \%$ of all eddies ( $20 \%$ of all anticyclonic-rotating eddies) in the eastern tropical North Atlantic are ACMEs. Zhang et al. (2017) found modewater eddies in all ocean basins and primarily in the upper $1000 \mathrm{~m}$.

More than a decade ago a dedicated observational programme was carried out in the Sargasso Sea in the western North Atlantic in order to better understand the physical-biogeochemical interactions in mesoscale eddies. The studies revealed that in ACMEs particularly intense deep chlorophyll $a$ layers are found which align with a maximum concentration of diatoms and maximum productivity (McGillicuddy et al., 2007). The high productivity was explained by the "eddy-wind interaction" concept (McGillicuddy et al., 2007, going back to a work by Dewar and Flierl, 1987) based on an Ekman divergence that is generated from the horizontal gradient in wind stress across anticyclonic rotating eddies. While the productivity is evident from observations, the concept was questioned (Mahadevan et al., 2008). High-resolution ocean model simulations, comparing runs with or without eddy-wind interaction, reproduced only a marginal impact on ocean productivity (but a strong impact on physics; Eden and Dietze, 2009). A tracer release exper- iment within an ACME revealed a vertical flux in the order of magnitude (several metres per day) as calculated based on the eddy-wind interaction concept (Ledwell et al., 2008).

Levy et al. (2012) summarized the submesoscale upwelling at fronts in general, not specifically for mesoscale eddies, and the impact on oceanic productivity. A key role is played by the vertical flux of nutrients into the euphotic zone, either by advection along outcropping isopycnals or by mixing. Moreover, eddies are retention regions (d'Ovidio et al., 2013) and the upwelled nutrients are kept in the eddy and utilized for new production (Condie and Condie, 2016).

In the tropical eastern North Atlantic ACMEs with very low oxygen concentrations in their cores have been observed (Karstensen et al., 2015). The generation of the low oxygen concentrations was linked to upwelling of nutrients and high productivity in the euphotic zone of the eddy followed by a remineralization of the sinking organic matter and accompanied by respiration. The temperature and salinity characteristics of the eddy core were found unaltered even after many months of westward propagation of ACMEs, indicating a well-isolated core. It was surprising to find a well-isolated eddy core, while in parallel an enhanced vertical nutrient flux is required to maintain the high productivity in the eddy.

A measure of the importance of local rotational effect relative to the Earth's rotation is given by the Rossby number defined as $R o=\frac{\zeta}{f}$, and where $\zeta=\frac{\partial v}{\partial x}-\frac{\partial v}{\partial y}$ is the vertical component of the relative vorticity ( $u$ and $v$ are zonal and meridional velocities, respectively) and $f$ the planetary vorticity. Planetary flows have small $R o$, say up to $\sim 0.2$, but local rotational effects gain importance with $R o$ approaching 1 , for example in eddies and fronts.

The horizontal velocity shear of mesoscale eddies creates a negative (positive) $\zeta$ in anticyclonic (cyclonic) rotating eddies. The $\zeta$ modifies $f$ to an "effective planetary vorticity" $\left(f_{\text {eff }}=f+\frac{\zeta}{2}\right)($ Kunze, 1985; Lee and Niiler, 1998). Negative $\zeta$ of anticyclonic-rotating eddies results in a $f_{\text {eff }}<f$ in their cores. In the region outward from the maximum swirl velocity of an anticyclonic eddy, towards the surrounding waters, a positive $\zeta$ "ridge" is created where $f_{\text {eff }}>f$ (e.g. Halle and Pinkel, 2003). The local modification of $f$ has implications for the propagation of near-inertial internal waves (NIWs): in the core of an anticyclonic-rotating eddy $\left(f_{\text {eff }}>f\right)$ the NIW become superinertial and their vertical propagation speed increases (Kunze et al., 1995). In the ridge region of any anticyclonic-rotating eddy the NIWs experience a reduction in vertical speed, and they may reflect because $f_{\text {eff }}<f$. Downward propagation of NIWs may result in an accumulation of wave energy at some critical depth and eventually part of the energy is dissipated by buoyancy release through vertical mixing (Kunze, 1985; Kunze et al., 1995; Whitt and Thomas, 2013; Whitt et al., 2014).

In anticyclonic-rotating eddies the downward propagation of wave energy in the $f_{\text {eff }}<f$ region has been observed and modelled (Kunze, 1985; Gregg et al., 1986; Lee and Niiler, 1998; Koszalka et al., 2010; Joyce et al., 2013; Alford et al., 
2016). Lee and Niiler (1998) simulated the NIW interaction with eddies (ACEs, CEs, ACMEs) and found vertical propagation of the NIW energy, the "inertial chimney". In the case of an ACME with a low squared buoyancy frequency $\left(N^{2}\right)$ layer they report on NIW energy accumulating below the eddy core and not inside as seen for ACEs. This change in energy accumulation was attributed to the vertical stratification of the ACME, in particular the two $N^{2}$ maxima that shield the low stratified eddy core. Kunze et al. (1995) analysed NIW energy propagation in an ACE. Within a critical layer at the inner sides of the ACE and where the $f_{\text {eff }}$ increases are $\geq 1$, the vertical propagation of NIWs is hampered, and energy accumulates, the bulk is released by turbulent mixing.

The vertical shear of the horizontal velocity that is generated by NIWs can eventually force overturning e.g. when approaching a critical layer (Kunze et al., 1995). The tendency of a stratified water column to become unstable through velocity shear $S=\sqrt{\left(\frac{\partial u}{\partial z}\right)^{2}+\left(\frac{\partial v}{\partial z}\right)^{2}}$ can be estimated from the gradient Richardson number $R i=N^{2} / S^{2}$. A $R i<1 / 4$ has been found to be a necessary condition for the shear to overcome the stratification and to generate overturning. However, Whitt et al. (2014) measured enhanced dissipation was with shear probes along the Gulf Stream front in several regions where NIW shear produced $R i<1$.

Recent observational studies using microstructure shear probe data report enhanced mixing in a narrow depth range of a local, vertical $N^{2}$ maximum, above and below the low stratified ACME core (Sheen et al., 2015; Kawaguchi et al., 2016). By applying an internal wave ray model to the $N^{2}$ stability profile and vertical shear profile from outside and from inside of an ACME, Sheen et al. (2015) could show that only a very limited range of incident angles of internal waves could propagate into the eddy core. Most NIWs encounter a critical layer above and below the eddy, in the regions where they observed enhanced mixing. Halle and Pinkel (2003) analysed NIW interaction with eddies having an ACME-like vertical structure in the Arctic and explained the low internal wave activity in the core as the result of an increase (order of magnitude) in wave group speed caused by low $N^{2}$ accompanied by lowering of wave energy density. Krahmann et al. (2008) reported observations of enhanced NIW energy in the vicinity of a Meddie. Meddie signatures of thermohaline layering at the eddy periphery have often been observed together with the occurrence of critical layers that support the energy transfer from the mesoscale to the submesoscale (Hua et al., 2013).

In this paper we investigate the hydrography, currents, and biogeochemical characteristics of a low oxygen ACME and its temporal evolution. High-resolution underwater glider and ship data allow us to describe the eddy structure at submesoscale resolution. Characteristics of a low oxygen ACME found in the eastern tropical North Atlantic are provided. The paper is part of a series of publications that report on differ- ent genomic, biological, and biogeochemical aspects of this eddy (Löscher et al., 2015; Hauss et al., 2016; Fiedler et al., 2016; Schütte et al., 2016b).

\section{Data and methods}

Targeted eddy surveys are logistically challenging. Eddy locations can be identified using real-time satellite SLA data. To further differentiate a positive SLA (indicative of anticyclonic-rotating eddies) into either an ACE or an ACME the SST anomaly across the eddy was additionally inspected, because ACMEs (ACEs) in the eastern tropical North Atlantic show a cold (warm) SST anomaly (Schütte et al., 2016a, b). For further evidence, Argo profile data were inspected to detect anomalously low temperature/salinity signatures also indicative of low oxygen ACMEs in the region (Karstensen et al., 2015; Schütte et al., 2016b). In late December 2013 a candidate eddy was identified through this mechanism and in late January 2014 a pre-survey was initiated, making use of autonomous gliders. After confirmation that the candidate eddy was indeed a low oxygen ACME, two ship surveys (ISL_00314, M105; Fiedler et al., 2016) and further glider surveys followed.

\subsection{Glider surveys}

Data from glider IFM12 and glider IFM13 were used in this study (Fig. 1). Glider IFM12 surveyed temperature, salinity, and oxygen to a depth of $500 \mathrm{~m}$ as well as chlorophyll $a$ fluorescence and turbidity to $200 \mathrm{~m}$ depth. Glider IFM13 surveyed temperature, salinity, and oxygen to a depth of $700 \mathrm{~m}$ as well as chlorophyll $a$ fluorescence and turbidity to $200 \mathrm{~m}$ depth. Glider IFM13 was also equipped with a nitrate sensor that sampled to $700 \mathrm{~m}$ depth.

For one full eddy survey of glider IFM12 (Fig. 1) we combined data from 3 to 5 February and from 7 to 10 February 2014 because, due to technical problems, data were not recorded in between these periods. Glider IFM13 surveyed one full eddy section from 3 to 7 April 2014. All glider data were internally recorded as a time series along the flight path, while for the analysis the data were linearly interpolated onto a regular pressure grid of $1 \mathrm{dbar}$ resolution. For the purposes of this study we consider the originally slanted profiles as vertical profiles.

\subsection{Glider sensor calibrations}

Both gliders were equipped with a pumped CTD (conductivity, temperature, and depth) and no evidence for further time lag correction of the conductivity sensor was found. Oxygen was recorded with AADI Aanderaa optodes (model 3830). The optodes were calibrated in reference to SeaBird SBE43 sensors mounted on a regular ship-based CTD, which in turn were calibrated using Winkler titration of water samples (see Hahn et al., 2014). Considering the full oxygen range, a root 
(a)

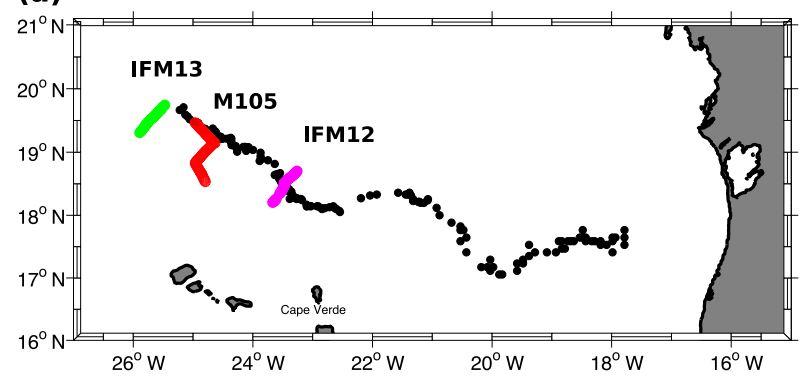

(b)

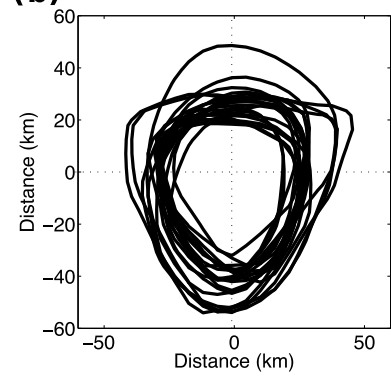

Figure 1. (a) Positions of the glider IFM12 (magenta) and IFM13 (green) surveys and the M105 ship survey (red dots). The Mauritanian coast is in the east, the Cape Verde Islands in the south. The black dots represent the sea level anomaly (SLA) based estimate of the eddy trajectory (see e.g. Fiedler et al., 2016). (b) Last closed geostrophic contours from SLA analysis during the IMF12 survey projected on the eddy centre.

mean square (rms) error of $3 \mu \mathrm{mol} \mathrm{kg} \mathrm{kg}^{-1}$ is found. However, for calibrating at the chemically forced $0 \mu \mathrm{mol} \mathrm{kg}-1$ oxygen, the rms error is smaller and about $1 \mu \mathrm{mol} \mathrm{kg}{ }^{-1}$. The calibration process also removes a large part of the effects of the slow optode response time via a reverse exponential filter (time constants were 21 and $23 \mathrm{~s}$ for IFM12 and IFM13, respectively). As there remained some spurious difference between down and up profiles we averaged upcast and downcast profiles to further minimize the slow sensor response problem in high gradient regions, particularly at the mixed layer base. The optical (Wetlabs ECO-PUC) chlorophyll $a$ fluorescence and turbidity data were not calibrated against bottle samples; only the factory calibration is applied. We subtracted a dark (black tape on sensor) offset value and the data are given here in relative units.

The nitrate $\left(\mathrm{NO}_{3}^{-}\right)$measurements on glider IFM13 were collected using a Satlantic Deep SUNA sensor. The SUNA emits light pulses and measures spectra in the ultraviolet range of the electromagnetic spectrum. It derives the $\mathrm{NO}_{3}^{-}$ concentration from the concentration-dependent absorption over a $1 \mathrm{~cm}$ long path through the sampled seawater. During the descents of the glider the sensor was programmed to collect bursts of five measurements every $20 \mathrm{~s}$ or about every $4 \mathrm{~m}$ in the upper $200 \mathrm{~m}$ and every $100 \mathrm{~s}$ or about every $20 \mathrm{~m}$ below $200 \mathrm{~m}$. The sensor had been factory calibrated 8 months prior to the deployment. The spectral measurements of the SUNA were post-processed using Satlantic's SUNACom software, which implements a temperature and salinity dependent correction to the absorption (Sakamoto et al., 2009). The SUNA sensors' light source is subject to aging which results in an offset $\mathrm{NO}_{3}^{-}$concentration (Johnson et al., 2013). To determine the resulting offset, $\mathrm{NO}_{3}^{-}$concentrations measured on bottle samples by the standard wet-chemical method were compared against the SUNA-based concentrations. The glider recorded profiles close to the CVOO mooring observatory (see Fiedler et al., 2016) at the beginning and end of the mission. These were compared to the mean concentrations of ship samples taken in the vicinity of the
CVOO location (Fiedler et al., 2016). In addition we compared glider measurements within the ACME to $\mathrm{NO}_{3}^{-}$samples from the ship surveys performed during the eddy experiment (see Löscher et al., 2015; Fiedler et al., 2016). The comparison showed on average no offset $\left(0.0 \pm 0.2 \mu \mathrm{mol} \mathrm{kg}{ }^{-1}\right)$. However, near the surface the bottle measurements indicated $\mathrm{NO}_{3}^{-}$concentrations below $0.2 \mu \mathrm{mol} \mathrm{kg}{ }^{-1}$ at $\mathrm{CVOO}$, while the SUNA delivered values of about $1.8 \mu \mathrm{mol} \mathrm{kg}^{-1}$ possibly related to technical problems near the surface. We thus estimate the accuracy of the $\mathrm{NO}_{3}^{-}$measurements to be better than $2.5 \mu \mathrm{mol} \mathrm{kg}-1$ with a precision of each value of about $0.5 \mu \mathrm{mol} \mathrm{kg}{ }^{-1}$.

All temperature and salinity data are reported in reference to TEOS-10 (IOC et al., 2010) and as such we report absolute salinity $\left(S_{\mathrm{A}}\right)$ and conservative temperature $(\Theta)$. Calculations of relevant properties (e.g. buoyancy frequency, oxygen saturation) were done using the TEOS-10 MATLAB toolbox (McDougall and Barker, 2011). We came across one problem related to the TEOS-10 thermodynamic framework when applied to isolated eddies. Because the eddies transfer properties nearly unaltered over large distances the application of a regional (observing location) correction for the determination of the $S_{\mathrm{A}}$ (McDougall et al., 2012) seems questionable. In the case of the surveyed eddy the impact was tested by applying the ion composition correction from $17^{\circ} \mathrm{W}$ (eddy origin) and compared with the correction at the observational position, more than $700 \mathrm{~km}$ to the west, and a salinity difference of a little less than $0.001 \mathrm{~g} \mathrm{~kg}^{-1}$ was found.

\subsection{Ship survey}

Data from two ship surveys have been used, surveying about 6 weeks after the first glider survey (and 3 weeks before the last glider survey) on the same eddy (Fig. 1): R/V Islandia cruise ISL_00314 performed sampling between 5 and 7 March 2014 and R/V Meteor cruise M105 sampled on 18 and 19 March 2014. From M105 we make use of the CTD data and the water current data recorded with a vessel mounted $75 \mathrm{kHz}$ Teledyne RDI acoustic Doppler current 
profiler (ADCP). The data were recorded in $8 \mathrm{~m}$ depth cells and standard processing routines were applied to remove the ship speed and correct the transducer alignment in the ship's hull. The final data were averaged in 15 min intervals. Only data recorded during steaming (defined as a ship speed larger than $6 \mathrm{kn}$ ) are used for evaluating the current structure of the eddy. It should be mentioned that the inner core of the eddy shows a gap in velocity records, which is caused by very low backscatter particle distribution (size about 1 to $2 \mathrm{~cm}$ ) (see Hauss et al., 2016, for a more detailed analysis of the backscatter signal, including net zooplankton catches). In order to provide a hydrography and oxygen framework for comparing ship currents and glider section data, we interpolated data from eight deep $(>600 \mathrm{~m})$ CTD stations performed during the eddy survey, and estimated oxygen and density distributions across the eddy. Because only a few stations have been sampled (in the eddy and at the eddy edge) during RV Islandia ISL_00314 (Fiedler et al., 2016), we use these data only in our $\mathrm{NO}_{3}^{-}$/oxygen analysis.

More information about other data acquired during M105 and ISL_00314 in the eddy is given elsewhere (Löscher et al., 2015; Hauss et al., 2016; Fiedler et al., 2016).

\section{Results and discussion}

\subsection{Vertical eddy structure and its temporal evolution}

In order to compare the vertical structure of the eddy from the three surveys, all sections were referenced to "kilometre distance from the eddy core" as the spatial coordinate, while the "centre" was selected based on visual inspection for the largest vertical extent of the low oxygen core defined by oxygen concentrations below $40 \mu \mathrm{mol} \mathrm{\textrm {kg } ^ { - 1 }}$. In all three sections the core is found in the centre of the eddy (Fig. 2), extending over the depth range from the mixed layer base (50 to $70 \mathrm{~m}$ ) down to about $200 \mathrm{~m}$ depth. The upper and lower boundary aligns with the curvature of isopycnals. Considering the whole section across the eddy, it can be seen that towards the centre of the eddy the isopycnals show an upward bending in an upper layer (typically associated with cyclonicrotating eddies) and a downward bending below (associated with anticyclonic-rotating eddies) which is characteristic of ACMEs.

During the first survey (IFM12), lowest oxygen concentrations of about $8 \mu \mathrm{mol} \mathrm{kg}{ }^{-1}$ were observed in two vertically separated cores at about 80 and $120 \mathrm{~m}$ depth, while in between the two cores, oxygen concentrations increased to about $15 \mu \mathrm{mol} \mathrm{kg}{ }^{-1}$. About 6 weeks later, during the M105 ship survey, lowest concentrations of about $5 \mu \mathrm{mol} \mathrm{kg}-1$ were observed, centred at about $100 \mathrm{~m}$ depth and without a clear double minimum anymore, based on six CTD stations. During the last glider survey (IFM13), another three weeks after the ship survey, the minimum concentrations were $<3 \mu \mathrm{mol} \mathrm{kg}^{-1}$ and showed in the vertical a single min-
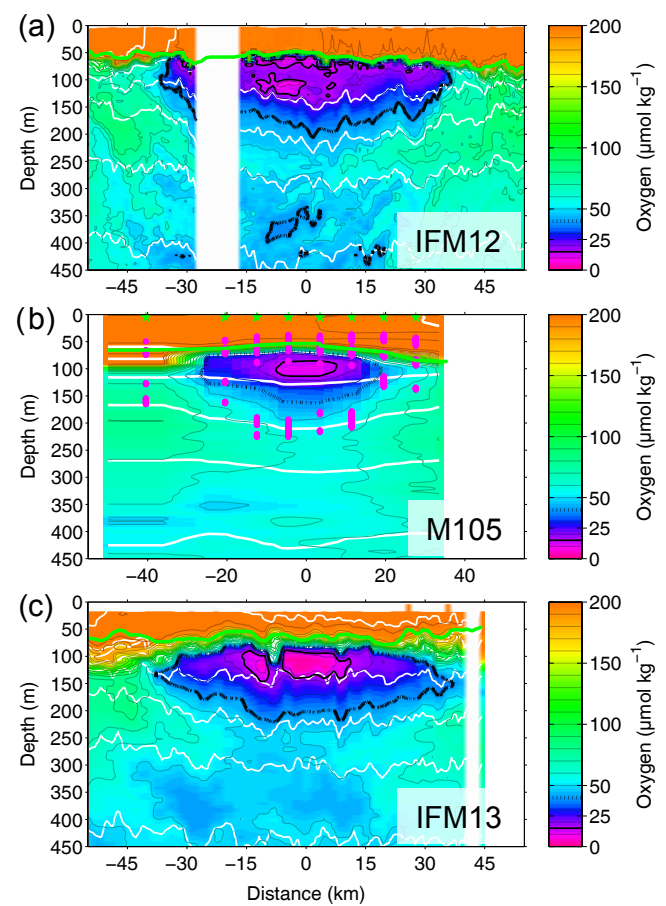

Figure 2. Oxygen distribution from the three eddy surveys (see Fig. 1) in reference to distance $(0 \mathrm{~km}$ is set at a subjectively selected eddy centre): (a) glider IFM12, (b) ship M105, and (c) glider IFM13. The $15 \mu \mathrm{mol} \mathrm{kg}{ }^{-1}\left(40 \mu \mathrm{mol} \mathrm{kg}{ }^{-1}\right)$ oxygen contour is indicated as a bold (broken) black line. Selected density anomaly contours are shown as white lines $\left(\Delta \sigma=0.2 \mathrm{~kg} \mathrm{~m}^{-3}\right)$. The green line indicates the mixed layer base. The oxygen contour in (b) was gridded based on the eight CTD stations (locations indicated by the green stars at 0 dbar) and mapped to a linear section in latitude, longitude. In (b) the magenta dots indicate positions of local $\mathrm{N}^{2}$ maxima in the CTD profiles.

imum centred at about $120 \mathrm{~m}$. The intensification of the minimum (by about $5 \mu \mathrm{mol} \mathrm{kg}{ }^{-1}$ in 2 months) is assumed here to be a result of continued respiration without balancing lateral/vertical mixing oxygen supply. It is important to note that during the glider survey the eddy performed about one full rotation and hence we expect less impact of the spatial variability in our sampling of the core. Underneath the eddy core, and best seen in the $40 \mu \mathrm{mol} \mathrm{kg}-1$ oxygen contour below $350 \mathrm{~m}$ at about $0 \mathrm{~km}$ (centre), an increase in oxygen over time is found, indicating supply of oxygen from surrounding waters. Comparing the two glider surveys (Fig. 2), a broadening of the gradient zone at the upper boundary of the core is observed. Overall the upper boundary of the core during the first survey aligned tightly with the mixed layer base, giving the core the shape of a plano-convex lens, while the lens developed into a biconvex shape before the second glider survey (also seen in the ship survey, Fig. 2b).

The SLA data analysis for the eddy (see Schütte et al., 2016b, for details) suggests a formation in the Mauritanian upwelling region (Fig. 1). The composite of the outermost 
(a)
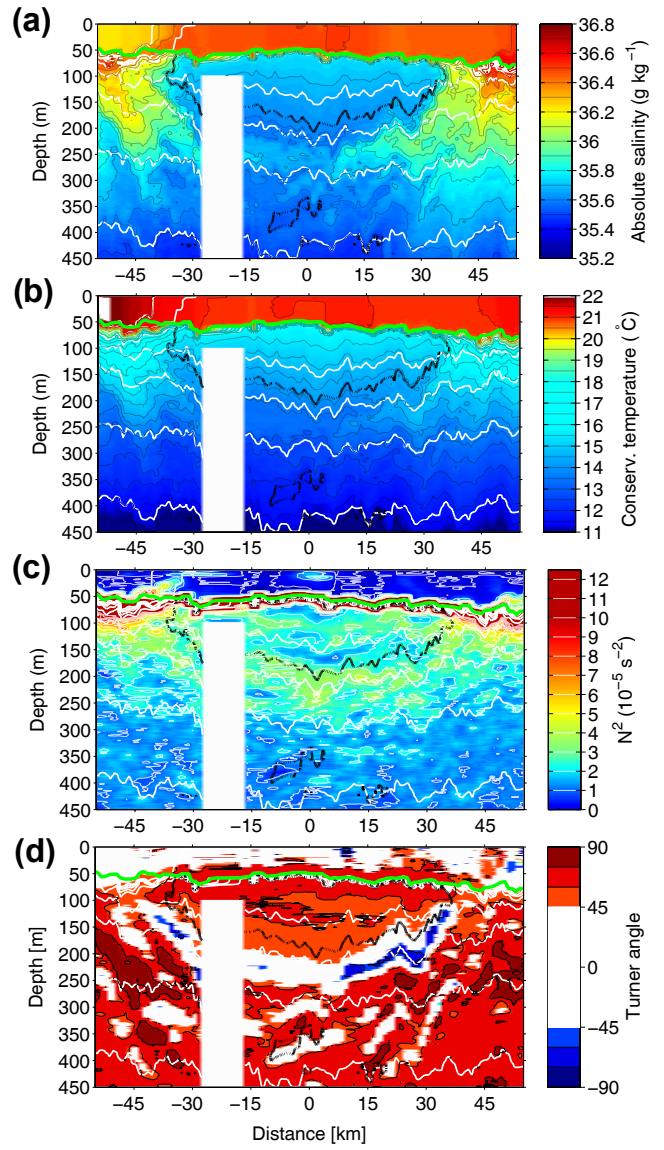

Figure 3. (a) $S_{\mathrm{A}}$, (b) $\Theta$, (c) $N^{2}$, and (d) Turner angle (only segments $\mid 45$ to $90 \mid$ are shown) from the IFM12 survey. The thick black broken line indicates the $40 \mu \mathrm{mol} \mathrm{kg}{ }^{-1}$ oxygen concentration indicating the low oxygen core (see Fig. 2). The green line indicates the mixed layer base. Selected density anomaly contours are shown as white lines $\left(\Delta \sigma=0.2 \mathrm{~kg} \mathrm{~m}^{-3}\right)$.

("last") closed geostrophic contour of the eddy (Fig. 1, right) revealed a diameter of about $60 \mathrm{~km}$, which is in accordance with the dimensions of the vertical structures observed from the glider and the ship (Figs. 2 and 3). The eddy core is composed of a fresh and cold (Figs. 3a, b and 4a) water mass that matches the characteristics of South Atlantic Central Water (SACW; Fiedler et al., 2016) and is a typical composition for low oxygen eddies in the eastern tropical North Atlantic (Karstensen et al., 2015; Schütte et al., 2016a, b). The properties confirm that the ACME was formed in the coastal area off Mauritania, as suggested by the SLA analysis (Schütte et al., 2016b; Fig. 1, left). Layering of properties, as seen in oxygen (Fig. 2), is also observed in $S_{\mathrm{A}}$ and $\Theta$ (Fig. 3) underneath the eddy core. In the depth range between 160 and $250 \mathrm{~m}$ the layers are aligned with density contours and suggest isopycnal transport processes, while below that depth range, and at the edges of the eddy core, the thermohaline intrusions cross density surfaces.
The low oxygen core of the ACME is well separated from the surrounding water through maxima in $N^{2}$ (Fig. 3c). The most stable conditions ( $N^{2}$ about 3 to $5 \times 10^{-4} \mathrm{~s}^{-2}$; compare Fig. 4a) are found along the upper boundary of the core and aligned with the mixed layer base (changed from 50 to $70 \mathrm{~m}$ between IFM12 and IFM13, respectively). $\Theta\left(S_{\mathrm{A}}\right)$ differences across the mixed layer base were large, about 5 to $6 \mathrm{~K}$ $\left(0.7-1.0 \mathrm{~g} \mathrm{~kg}^{-1}\right)$, but over time the mixed layer base widened from $8 \mathrm{~m}$ (glider IFM12 survey) to $16 \mathrm{~m}$ (M105 ship) and to $40 \mathrm{~m}$ (glider IFM13 survey) (Fig. 4a).

At the lower side of the ACME the $N^{2}$ maximum was an order of magnitude weaker $\left(N^{2} \sim 4 \times 10^{-5} \mathrm{~s}^{-2}\right)$, but separates the eddy core well from the surrounding waters. The layering in properties is also seen in alternating patterns in $N^{2}$ at the rim and below the eddy. A possible driver for mixing in this region is double diffusion, and therefore the stability ratio $R_{\rho}=\frac{\alpha^{\theta} \Theta_{z}}{\beta^{\theta}\left(S_{\mathrm{A}}\right)_{z}}$ (McDougall and Barker, 2011) was calculated. $R_{\rho}$ is the ratio of the vertical ( $z$ ) gradient in $\Theta$, weighted by the thermal expansion coefficient $\left(\alpha^{\Theta}\right)$, over the vertical $(z)$ gradient in $S_{\mathrm{A}}$, weighted by the haline contraction coefficient $\left(\beta^{\Theta}\right)$ (Fig. 3d). For convenience $R_{\rho}$ is converted here to a Turner angle $(T u)$ using the four-quadrant arctangent. For $T u$ between -45 and $-90^{\circ}$ the stratification is susceptible to salt-finger type double diffusion, while $T u+45$ to $+90^{\circ}$ indicate susceptibility to diffusive convection. Regions where double diffusion most likely occurs are found for $T u$ close to $\pm 90^{\circ}$.

In the core of the eddy the $T u$ indicates a weak salt-finger regime ( $T u$ values close to $+45^{\circ}$; Fig. $3 \mathrm{~d}$ ); however, no welldeveloped thermohaline gradients exist and thus no enhanced vertical mixing by double diffusion is expected to take place here. In contrast, below the low oxygen core and along the thermohaline layering structures, the $T u$ patterns show values within the \pm 45 to $\pm 90^{\circ}$ range, even getting close to $\pm 90^{\circ}$. At both edges ( \pm 15 to $\pm 45 \mathrm{~km}$ ) a band of diffusive convection is seen and here is where water of the core potentially exchanges/erodes (see below). The $T u$ pattern does not align with the tilting of the isopycnals, but crosses isopycnals. The thermohaline gradients are most likely created by intrusions of cold and saline SACW from the core into the surrounding warm and salty water. The core itself shows a $\Theta / S_{\mathrm{A}}$ characteristic of constant slope over time (Fig. 4c) and indicating weak mixing with surrounding water. The salinity offset between gliders IFM12 and IFM13 is about $-0.01 \mathrm{~g} \mathrm{~kg}^{-1}$, which could indicate a weak exchange of the whole core (all densities) with surrounding water, but also is close to the expected accuracy of the salinity data. What clearly is evident is a shrinking of the core $\Theta / S_{\mathrm{A}}$ range from 15.7/13.7 to $15.2 / 13.9^{\circ} \mathrm{C}$.

At the edge region of the eddy (Fig. 4e to g) the mixed layer base is wider and the gradient is less sharp (Fig. 4e) when compared with the centre of the eddy (Fig. 4a). No low $N^{2}$ core and thus no double $N^{2}$ maxima are found, but just one maximum (much weaker $N^{2} \sim 10^{-4} \mathrm{~s}^{-2}$ ) at the mixed 

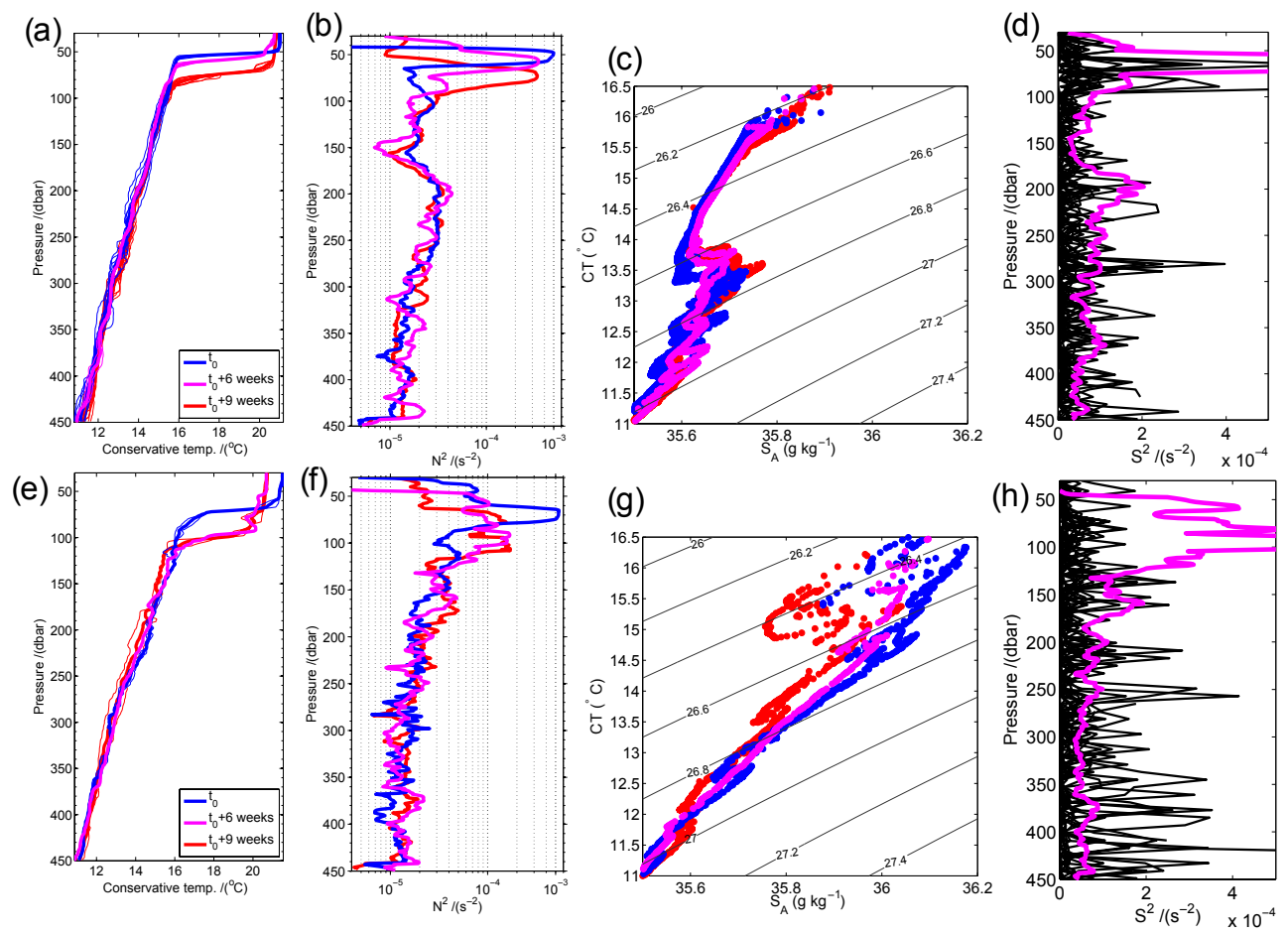

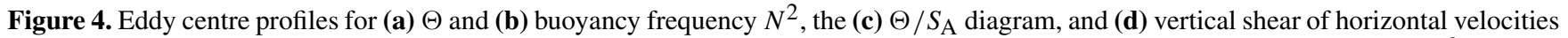
$(S)$ squared. (e-h) as $(\mathbf{a}-\mathbf{d})$ but for selected profiles at the edge of the eddy. In $(\mathbf{d}, \mathbf{h})$ the magenta line indicates the magnitude of $S^{2}$ required to overcome the local stability $\left(4 \cdot N^{2}\right)$.

layer base (Fig. 4f) is found, at least for the ship (M105) and the second glider survey (IFM13). Overall the $N^{2}$ maxima are located deeper in the water column. The $\Theta / S_{\mathrm{A}}$ diagram (Fig. $4 \mathrm{~g}$ ) shows more of the characteristics of the surrounding waters but thermohaline intrusions for temperatures below $13.8^{\circ} \mathrm{C}$ which have a water mass core moving along isopycnals.

The ADCP zonal velocity data from the M105 ship survey show a baroclinic, anticyclonic-rotating flow, with a maximum swirl velocity of about $0.4 \mathrm{~m} \mathrm{~s}^{-1}$ at about $70 \mathrm{~m}$ depth and $30 \mathrm{~km}$ distance from the eddy centre (Fig. 5a). The maximum rotation speed (see as an approximation the zonal velocity, Sect. 5a) decreases nearly linearly to about $0.1 \mathrm{~m} \mathrm{~s}^{-1}$ at $380 \mathrm{~m}$ depth. Considering the translation speed of the eddy of 3 to $5 \mathrm{~km} \mathrm{day}^{-1}$ (Schütte et al., 2016b), the nonlinearity parameter $\alpha$, relating maximum swirl velocity to the translation speed, is much larger than 1 (about 6.5 to 11 in the depth level of the low oxygen core) and indicates a high coherence of the eddy (Chelton et al., 2011). At the depth of the maximum swirl velocity, and considering the eddy radius of $30 \mathrm{~km}$, a full rotation would take about 5 days, but even longer for the deeper levels.

To investigate the flow field we decompose the observed velocity $(u, v)$ into a mean $(\bar{u}, \bar{v})$ and a fluctuating part $\left(u^{\prime}, v^{\prime}\right)$ by applying a $120 \mathrm{~m}$ boxcar filter (a longer filter length does not significantly change the results) to the ob- served profile data (here for the zonal velocity $u$, Fig. 5a, b, c):

$u=\bar{u}+u^{\prime}$.

The $\bar{v}$ field is here interpreted as the mesoscale or "subintertial" flow (Fig. 5b) and shows a baroclinic anticyclonic circulation with velocity maximum close to the surface at $\pm 30 \mathrm{~km}$ in the eddy-relative coordinates. The fluctuating part $\left(u^{\prime}\right.$; Fig. 5c) is dominated by alternating currents with about 80 to $100 \mathrm{~m}$ wavelength. This layering of velocity finestructure resembles layering in properties (Figs. 2 and 3) and indicates shears most likely introduced by the propagation of NIWs (Joyce et al., 2013; Halle and Pinkel, 2003). Largest $u^{\prime}$ currents are found in two regions: (i) in the upper $150 \mathrm{~m}$ in the vicinity of the mesoscale velocity maximum at the southwestern side of the eddy (Reg. 1) and (ii) in the 250 to $450 \mathrm{~m}$ depth range below the core (Reg. 2). We estimated the progressive vector diagram (PVD) of the $u^{\prime}$ fluctuating velocity components for the two regions and found cyclonic rotation, indicating the downward vertical energy propagation of NIWs (Leaman and Sanford, 1975). However, for the region at the eddy edge (Reg. 1) the levels below $150 \mathrm{~m}$ depth show no rotation in the PVD, suggesting that the downward energy propagation does not continue, which may suggest either reflecting or dissipation (e.g. Kunze et al., 1995).

From the subinertial velocity field the relative vorticity was calculated and subsequently the $f_{\text {eff }}$ across the eddy 

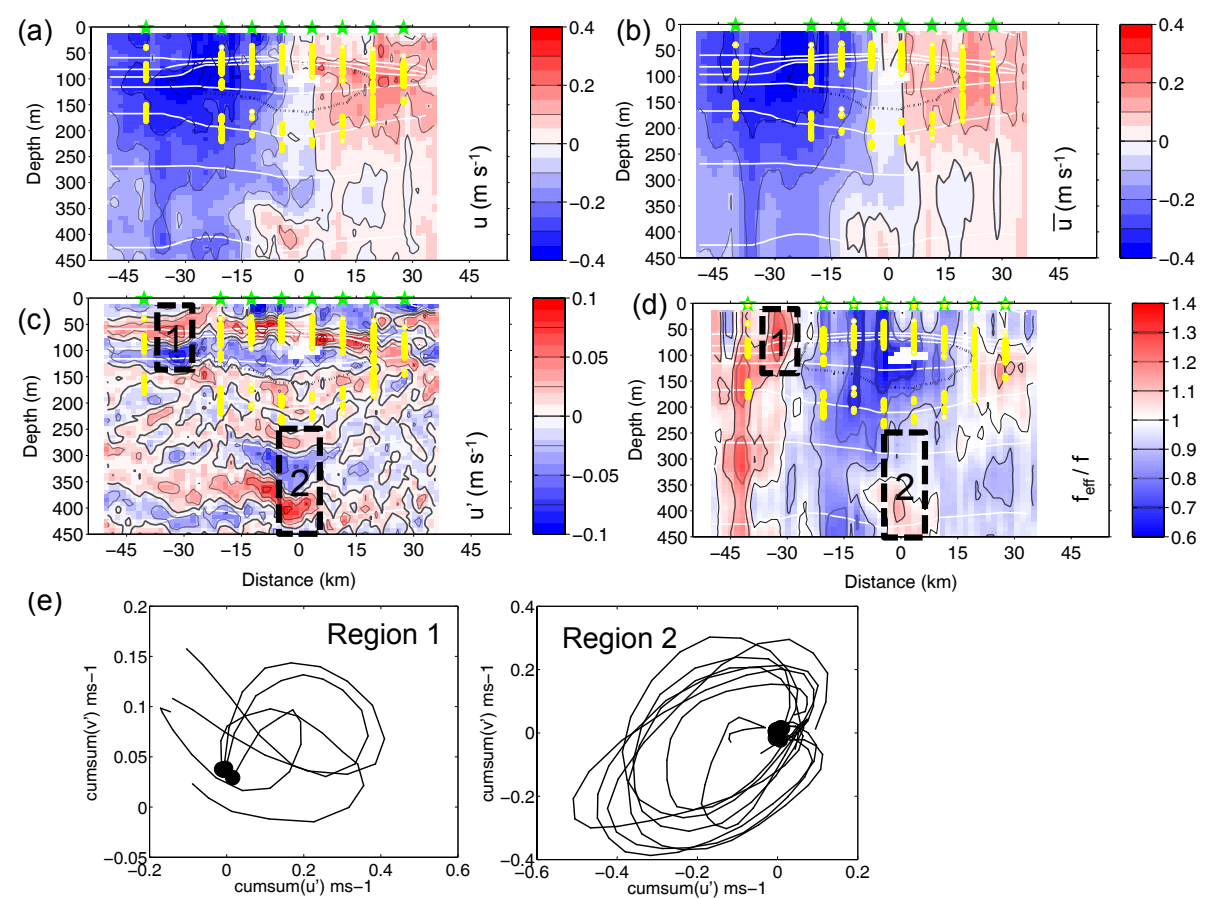

Figure 5. (a) Observed zonal velocity, (b) boxcar filtered zonal velocity (applied over $120 \mathrm{~m}$ ), and the (c) difference between observed and boxcar filtered velocities. The thick black broken line indicates the $40 \mu \mathrm{mol} \mathrm{kg}{ }^{-1}$ oxygen concentration; white contours are selected density anomaly contours $\left(\Delta \sigma=0.2 \mathrm{~kg} \mathrm{~m}^{-3}\right)$ determined by gridding CTD profile data (see the green stars at 0 dbar for station positions). The yellow dots indicate the $N^{2}$ maximum from CTD profile data. (d) Ratio between the effective Coriolis parameter ( $\left.f_{\text {eff }}\right)$ and local Coriolis parameter (f). (e) Progressive vector diagram of $u^{\prime} / v^{\prime}$ for regions 1 (250 to $450 \mathrm{~m}$ depth, seven profiles) and 2 (20 to $140 \mathrm{~m}$; three profiles) (see $\mathbf{c}$ and $\mathbf{d}$ for locations); the black dots mark the shallowest depth

(Fig. 5d). Within the core of the anticyclone $(\zeta<0)$ a $f_{\text {eff }}<$ $f$ with $R o=-0.7$ between 70 and $150 \mathrm{~m}$ is found. At the transition between eddy and surrounding waters $\zeta$ changes sign and a positive vorticity ridge $\left(f_{\text {eff }} / f>1.3\right)$ is observed. Likewise, a local increase in $f_{\text {eff }}$ is seen underneath the core in the eddy centre. In both regions large amplitude $u^{\prime}$ (Fig. 5c) and $v^{\prime}$ (not shown) are observed as well as downward NIW energy propagation (from PVD; Fig. 5e).

An aliasing occurs through the rotation of the inertial current vector during the survey time. Joyce et al. (2013), in their analysis of mid-latitude NIW propagation (inertial period $19 \mathrm{~h}$ ), applied a back rotation. However, at $19^{\circ} \mathrm{N}$ the inertial period is $36.7 \mathrm{~h}$ and the complete ADCP section was surveyed within $14 \mathrm{~h}$ (including station time). Because we primarily interpret station data, the aliasing effect should be small for the M105 data. In contrast, the glider sections took several days and many inertial periods, and thus a mixture of time-space variability is mapped in the property fields (Figs. 3 and 4). It is however interesting to note that the velocity and property layering still looks very similar and coherent across the different surveys, suggesting that the processes that drive the layering are rather long-lasting over several months.

\subsection{Eddy core isolation and vertical fluxes}

Karstensen et al. (2015) proposed a concept for the formation of a low oxygen core in a shallow ACME in the eastern tropical North Atlantic as a combination of isolating the eddy core against oxygen fluxes (primarily vertical) and high productivity and subsequent respiration of sinking organic material. The concept is in analogy to the formation of dead zones in coastal and limnic systems, hence the name "dead zone eddies". The key for high productivity is the transport of nutrients into the euphotic zone in the eddy.

We identified three areas in the eddy where we further analysed vertical transport and mixing: (Area I) the eddy core, bounded by $N^{2}$ maxima with a low stratification in between. (Area II) The layering regime underneath the low oxygen core with alternating velocity shear and density compensated, mainly salt-finger supporting thermohaline intrusions. (Area III) The high velocity shear zones at the southeastern edge of the eddy and underneath the eddy centre. We do not have direct mixing estimates (e.g. microstructure) but analyse the observed $S^{2}, N^{2}$, and $R i$ from the M105 ship survey data. Selected CTD $N^{2}$ profiles from the centre and the edge of the eddy are analysed in combination with ADCP fluctuation velocity $\left(u^{\prime}, v^{\prime}\right)$ shear, estimated from $8 \mathrm{~m}$ bin data (Fig. 4 d, h). To take the high-frequency temporal fluc- 
tuations in the velocity data into account we show here the velocity shear in the vicinity of the CTD station, considering all ADCP data recorded 30 min before until 60 min after the CTD station started. Based on the existing ( 1 dbar) $N^{2}$ we calculated a $S^{2}$ that satisfied a $R i<1 / 4$ (magenta line in Fig. 4d, h).

For the eddy core (Area I) a strong contrast to surrounding water masses is seen across the mixed layer base, but also laterally (Fig. 4c). Decreasing oxygen concentrations are observed in Area I over a period of 2 months, while the $\Theta / S_{\mathrm{A}}$ characteristics exhibit a stable slope (Fig. 4). Low mixing in the core of ACMEs has been explained from direct observations before. Sheen et al. (2015) and Kawaguchi et al. (2016) observed enhanced mixing at the $N^{2}$ maximum and found wave-wave interaction as a likely process for the mixing. They argued that, because of the $N^{2}$ maximum around the core, but also because of the low $N^{2}$ in the core, less wave energy can enter the core and mixing in the core is low. Halle and Pinkel (2003) argued that, because of the low $N^{2}$ in the core, the NIW energy density was low and hence less energy is available for mixing. Our observations do show that high mixing occurs at the $N^{2}$ maxima and that the core itself is a low mixing regime. The mixing to take place at the $N^{2}$ maximum is seen in a widening and deepening of the gradient zone at the mixed layer base in all sections and is even stronger towards the edges of the eddy (Figs. 2, 3, and $4 a)$. The consequence of vertical change from a high to a low mixing zone creates an "erosion" (outward directed mixing) of the core into the mixed layer. The erosion is linked to upwelling and thus it has implications for the oxygen and nutrient cycling, as will be discussed below.

In the layering shear regime underneath the eddy (Area II) we found that $R i$ approaches critical values (1/4) in layers of maximal NIW velocity-induced shear and thus may indicate generation of instabilities in these layers. Below the eddy the $S_{\mathrm{A}}$ gradients (Fig. 3a) do align with the wave crests, indicating the impact of intense strain, and thus a periodic intensification of $S_{\mathrm{A}}$ gradients, which in turn could enhance the susceptibility to double diffusive mixing (Fig. 3d). Likewise the $\Theta / S_{\mathrm{A}}$ diagram clearly shows the existence of thermohaline intrusions oriented along isopycnals.

Area III is where high $u^{\prime}$ shear is observed (Reg. 1 and Reg. 2; Fig. 5c, d). It is plausible to assume that a large fraction of the NIW energy that impacts the eddy originates from wind stress fluctuations (D'Asaro, 1985). The NIW energy propagation in the upper layer of the eddy (above the core) is downward, across the intense $N^{2}$ contours/mixed layer base, and possibly driving enhanced mixing (e.g. by wave-wave interaction as in Sheen et al., 2015). The Ri (Fig. 4d, h) indicates that at the mixed layer base where high shear and high $N^{2}$ are found. In the eddy core $N^{2}$ is low, but so is the shear (Fig. $4 \mathrm{~d})$. At the eddy edge ( $\sim-32 \mathrm{~km}$ distance), in the transition between maximum swirl velocity and the surrounding ocean, NIW energy is forced to propagate downward (see Fig. $4 \mathrm{~b}, \mathrm{~d}$ ) because $f_{\text {eff }} / f>1$ (Fig. 5b). The $R i$ distribution (Fig. 4h) for the M105 ship survey shows that $N^{2}$ is too high to be destabilized by the shear, at least at the location where the CTD profile was taken. However, we know that the NIWs have an amplitude of more than $0.1 \mathrm{~m} \mathrm{~s}^{-1}$ and a vertical scale of about 70 to $90 \mathrm{~m}$ (Fig. 4d). This is similar to observations at mid-latitude fronts (e.g. Whitt et al., 2014; Kunze and Sanford, 1984) where an inertial radius of about $2 \mathrm{~km}$ for an amplitude of $0.1 \mathrm{~m} \mathrm{~s}^{-1}$ has been found and thus such a wave covers a good part of the eddy front. Moreover, the magnitude of the fluctuation $\left(0.1 \mathrm{~m} \mathrm{~s}^{-1}\right)$ associated with the NIW accounts for about $25 \%$ of maximum swirl velocity at about $\sim-32 \mathrm{~km}$ at 50 to $120 \mathrm{~m}$ depth. The NIW phase velocity $\left(u^{\prime}\right.$; Fig. $\left.5 \mathrm{c}\right)$ is of a similar magnitude to the swirl velocity and thus susceptible to critical layer formation (Kawaguchi et al., 2016). For a Gulf Stream warm core ring, Joyce et al. (2013) found most instabilities and mixing close to the surface and where most horizontal shear in the baroclinic current is found (similar to our region 1; Fig. 5c, d). Evidence for vertical mixing to take place in this region is seen in upwelling of nitrate into the mixed layer/euphotic zone at about $100 \mathrm{~m}$ depth/distance of about $-32 \mathrm{~km}$ (see below; Fig. 7b). Underneath the eddy the vertical propagation of superinertial waves across the anticyclonic eddy is seen (Kunze et al., 1995) but into a region where $f_{\text {eff }} / f>1$ (Reg. 2 in Fig. 5c, d) and where $R i$ is getting critical, possibly related to a slowing of the energy propagation.

\subsection{Nutrient cycling in the eddy}

The productivity associated with the ACME requires the upward fluxes of nutrients into the euphotic zone. Schütte et al. (2016b) showed that the low oxygen ACMEs in the tropical eastern North Atlantic do have productivity maxima (indicated by enhanced ocean colour based chlorophyll $a$ estimates) to be more concentrated at the rim of the eddies. This observation suggests that the vertical flux is also concentrated at the rim of the eddy. Indeed, when inspecting the glider section data (Fig. 3) we do find evidence for upwelling being concentrated at the rim, although the mixed layer base is characterized by very stable stratification and large gradients (e.g. $0.3 \mathrm{~K} \mathrm{~m}^{-1}$ in temperature). Considering the first glider oxygen section (IFM12, Fig. 2a), the upper of the two separate oxygen minima is found very close to the depth of the mixed layer base and indicates that any exchange across the mixed layer by mixing processes must be very small. The number of particles might be approximated by the turbidity measurement from the glider (Fig. 6a, c). While the first survey had very high turbidity several tens of metres below the mixed layer base (Fig. 6a), the second glider survey showed much less particle load (Fig. 6c), indicating lower productivity across the eddy that may be related to a weakening of the vertical flux of nutrients into the euphotic zone. The fluorescence signal (Fig. 6b, d) indicates the first glider survey (IFM12, Fig. 6b) captured a bloom that occupied the whole mixed layer (note that the periods with low fluorescence align 

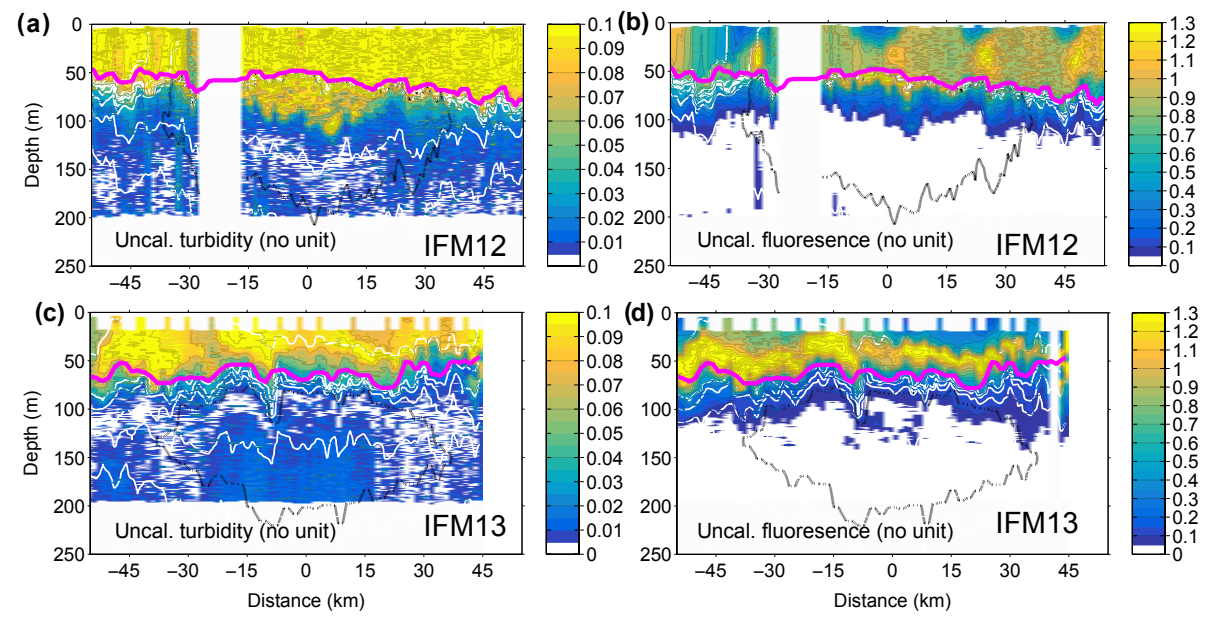

Figure 6. Uncalibrated turbidity (a, c) and chlorophyll-fluorescence (b, d) data from the glider IFM12 survey (a, b) and glider IFM13 survey (c, d). The magenta line denotes the base of the mixed layer; the broken black line is the extent of the low oxygen core (oxygen $\left.<40 \mu \mathrm{mol} \mathrm{kg}^{-1}\right)$.

with daylight periods and as such are generated by quenching) and as such intense nutrient supply and productivity. In contrast, the second glider survey (IFM13; Fig. 6d) shows a clear subsurface fluorescence maximum (about $10 \mathrm{~m}$ above the mixed layer base), indicating that the nutrient supply is primarily concentrated on mixed layer base exchange processes.

In order to interpret the low oxygen concentrations in terms of biogeochemical processes, the bulk remineralization of oxygen and nitrate is determined. The apparent oxygen utilization (AOU, Fig. 7a) is defined as the difference between measured oxygen concentration and the oxygen concentration of a water parcel of the given $\Theta$ and $S_{\mathrm{A}}$ that is in equilibrium with air (Garcia and Gordon, 1992, 1993). AOU is an approximation for the total oxygen removal since a water parcel left the surface ocean. The low oxygen concentrations in the core of the eddy are equivalent to an AOU of about $240 \mu \mathrm{mol} \mathrm{kg}^{-1}$ (Fig. 7a). Along with high AOU we also find very high $\mathrm{NO}_{3}^{-}$concentrations with a maximum of about $30 \mu \mathrm{mol} \mathrm{kg}{ }^{-1}$ (Fig. 7b). The corresponding AOU : $\mathrm{NO}_{3}^{-}$ratio outside the core is 8.1 and thus close to the classical 8.625 Redfield ratio (138/16; Redfield et al., 1963). However, in the core an $\mathrm{AOU}: \mathrm{NO}_{3}^{-}$ratio of $>16$ is found.

This high ratio indicates that less $\mathrm{NO}_{3}^{-}$is released during respiration (AOU increase) than expected for a remineralization process following a Redfieldian stoichiometry. By considering the remineralization outside the core (Fig. 7c) the respective $\mathrm{NO}_{3}^{-}$deficit can be estimated to up to 4$6 \mu \mathrm{mol} \mathrm{kg}{ }^{-1}$ for the highest $\mathrm{AOU}\left(\mathrm{NO}_{3}^{-}\right)$observations. By integrating $\mathrm{NO}_{3}^{-}$and $\mathrm{NO}_{3}^{-}$deficit over the core of the low oxygen eddy (defined here as the volume occupied by water with oxygen concentrations $<40 \mu \mathrm{mol} \mathrm{kg}{ }^{-1}$ ) we obtain an average $\mathrm{AOU}: \mathrm{NO}_{3}^{-}$ratio of about $20: 1$.
One way to interpret this deficit is by $\mathrm{NO}_{3}^{-}$loss through denitrification processes. Löscher et al. (2015) and Grundle et al. (2017) both found evidence for the onset of denitrification in the core of the ACME discussed here. Oxygen concentrations in the core are very low (about $3 \mu \mathrm{mol} \mathrm{kg}^{-1}$ ) and denitrification is possible. Evidence for denitrification in the core of the ACME was, however, demonstrated as being important for nitrous oxide $\left(\mathrm{N}_{2} \mathrm{O}\right)$ cycling at the nanomolar range (Grundle et al., 2017), and not necessarily for overall $\mathrm{NO}_{3}^{-}$losses, which are measured in the micromolar range. Grundle et al. (2017) showed by relating nitrogen and phosphorous cycling that in the core of the ACME the $\mathrm{NO}_{3}^{-}$losses were not detectable at the micromolar range. Thus, while denitrification may have played a minor role in causing the higher than expected $\mathrm{AOU}: \mathrm{NO}_{3}^{-}$ratio which we have calculated, it is unlikely that it contributed largely to the loss of $5 \%$ of all $\mathrm{NO}_{3}^{-}$from the eddy as estimated based on the observed $\mathrm{AOU}: \mathrm{NO}_{3}^{-}$ratios.

Alternatively, but perhaps not exclusively, the $\mathrm{NO}_{3}^{-}$recycling within the ACME could be the reason for the $\mathrm{NO}_{3}^{-}$ deficit. A high $\mathrm{AOU}: \mathrm{NO}_{3}^{-}$ratio could be explained through a decoupling of $\mathrm{NO}_{3}^{-}$and oxygen recycling pathways in the eddy and details about the vertical transport pathways of nutrients (erosion of the core). Based on the investigation of the possible vertical mixing/transport of nutrients (here $\mathrm{NO}_{3}^{-}$) the erosion of the eddy core plays a key role. In this scenario $\mathrm{NO}_{3}^{-}$molecules are used more than one time for the remineralization/respiration process, and therefore the $\mathrm{AOU}$ increases without a balanced, in a Redfieldian sense, $\mathrm{NO}_{3}^{-}$ remineralization. Such a decoupling can be conceptualized as follows (Fig. 8, left): consider an upward flux of dissolved $\mathrm{NO}_{3}^{-}$and oxygen in a given ratio with an amount of water that originates from the low oxygen core. The upward flux partitions when reaching the mixed layer; one part disperses 

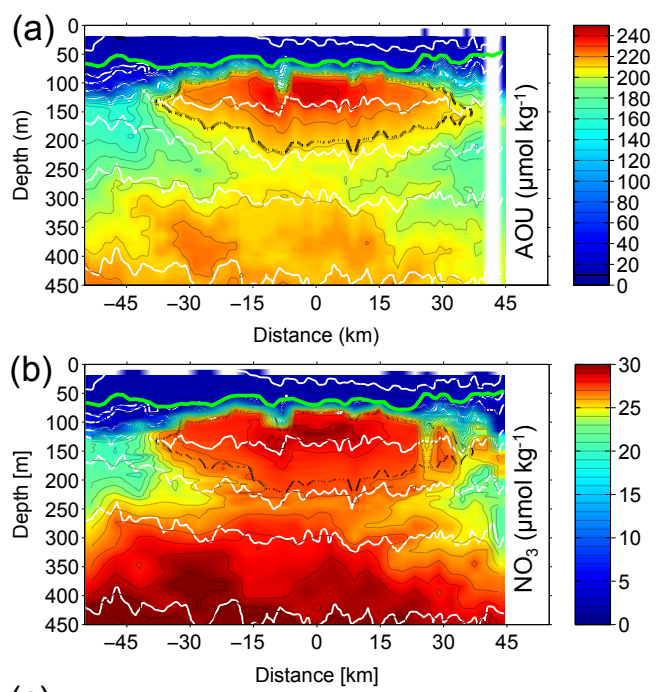

(c)

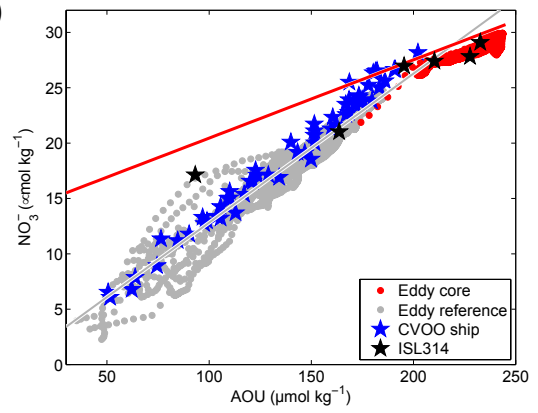

Figure 7. (a) $\mathrm{AOU}$ and (b) $\mathrm{NO}_{3}^{-}$from glider IFM13 survey. (c) AOU versus $\mathrm{NO}_{3}^{-}$for the depth range 90 to $250 \mathrm{~m}$ depth (red dots) glider IFM13 survey in the low oxygen core, (black dots) IFM13 glider survey close to CVOO, (blue stars) CVOO ship data, and (black star) the Islandia ISL_00314 eddy survey (see Fielder et al., 2016, for details on the surveys). The linear best fit to the glider data outside the eddy (grey line; slope 8.77) and inside the core (red line; slope 0.56) are shown.

in the open waters outside of the eddy, and the other part is kept in the eddy by retention (D'Ovidio et al., 2013). The upwelled $\mathrm{NO}_{3}^{-}$is utilized by autotrophs for primary production and thereby incorporated into particles as particulate organic nitrogen (PON) while the corresponding oxygen production is re-ventilated by air-sea oxygen flux. The PON sinks out of the mixed layer/euphotic zone and into the core of the eddy where remineralization of organic matter releases quickly some of the $\mathrm{NO}_{3}^{-}$originating from the core waters. In contrast, the upwelling of oxygen-deficient waters will drive an oxygen flux from the atmosphere into the ocean in order to reach chemical equilibrium. But because the stoichiometric equivalent of oxygen is exchanged with the atmosphere and therefore not transported back into the core by gravitational settling of particles, as is the case for nitrate (via PON), the respiration associated with the remineralization of the recycled nitrate will result in a net increase in AOU.

\section{Summary and conclusion}

Here we present a first analysis of the temporal evolution of a low oxygen ACME in the eastern tropical North Atlantic from high-resolution multidisciplinary glider and ship survey data. The low oxygen eddy has a diameter of about 70 to $80 \mathrm{~km}$ and a maximum swirl velocity of $0.4 \mathrm{~m} \mathrm{~s}^{-1}$ close to the mixed layer base and can be considered typical for the region (Schütte et al., 2016a, b). The eddy originated from the Mauritanian upwelling region (Schütte et al., 2016b; Fiedler et al., 2016) and had a distinct anomalously fresh and cold water mass in its low oxygen core. The core was located immediately below the mixed layer base (about 70 to $80 \mathrm{~m}$ ) down to a depth of 200 to $250 \mathrm{~m}$ in its centre. The core showed minimum oxygen concentrations of $8 \mu \mathrm{mol} \mathrm{kg} \mathrm{g}^{-1}$ during the first glider survey (February 2014) and $3 \mu \mathrm{mol} \mathrm{kg}^{-1}$ during the second glider survey, 9 weeks later. Enhanced productivity was estimated for the eddy (Fiedler et al., 2016), implying a vertical flux of nutrient rich waters to the euphotic zone/mixed layer, and is seen in high turbidity that reached during the first glider survey more than $50 \mathrm{~m}$ into the core (Fig. 6a).

A concept for the coexistence of an isolated, low oxygen core but surrounded by regions of enhanced mixing in an ACME was derived from analysis of observational data (Fig. 8). The eddy relative vorticity is negative in the core but positive at the transition outward from the swirl velocity maximum into the surrounding water ("positive vorticity ridges", Halle and Pinkel 2003). Distinct regions with $f_{\text {eff }}<$ $f$ (core) and $f_{\text {eff }}>f$ (transition eddy/surrounding waters) are created by the mesoscale flow. The $f_{\text {eff }} / f$ ratio indicates two different regimes of vertical propagation of NIW energy, as reported in numerous studies (e.g. Kunze, 1985; Kunze et al., 1995; Sheen et al., 2015; Halle and Pinkel, 2003). In $f_{\text {eff }}<f$ regions internal waves become superinertial and rapidly propagate downward. If these waves now propagate through a region of high vertical stratification $\left(N^{2}\right.$ maxima at the upper and lower boundaries of the core), they will have a high energy density, while if they propagate through low vertical stratification $\left(N^{2}\right.$ minimum in the core), they have low energy density. Numerical simulations (e.g. Koszalka et al., 2010) and observations (e.g. Sheen et al., 2015) report on high vertical mixing in regions with strong stratification (and low mixing in weakly stratified regions). Our observations show low $R i$ at the $N^{2}$ maxima, which suggests enhanced diapycnal mixing as occurring here.

When the superinertial waves encounter a $f_{\text {eff }}>f$ region they will undergo a reduction in vertical speed and the waves may eventually reflect (e.g. Halle and Pinkel, 2003) or dissipate (Kawaguchi et al., 2016). Indeed we observe critical $R i$ and a shear variance maximum in the velocity finestructure in these regions (Fig. 5, Regions 1 and 2). "Region 2", right below the centre of the eddy, coincides with where Lee and Niiler (1998) found a NIW energy maximum from their "inertial chimney" simulations of an ACME. Unfortu- 


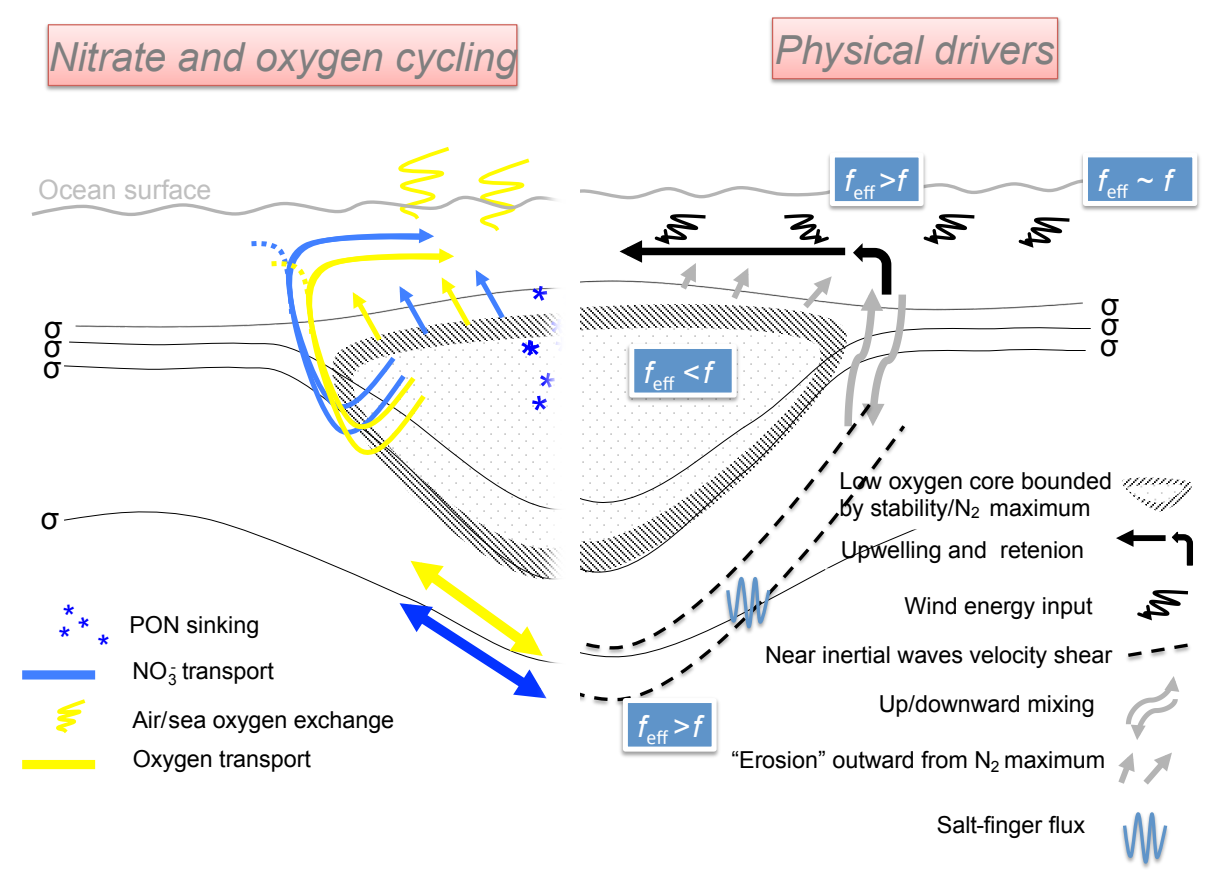

Figure 8. Conceptual view of the biogeochemical (left) and physical (right) processes responsible for creating a low oxygen ACME. The recycling of nitrate is decoupled from the oxygen cycling through PON. The transport at the flanks and the isolation of the eddy core are linked to the energy propagation of NIW. Vertical flux (upwelling and downwelling) of nutrient rich/low oxygen waters occurs at the boundaries and at the mixed layer base (outward). Eddy retention keeps upwelling waters in the euphotic zone of the eddy. Shear from NIW velocity fluctuations creates critical Ri underneath the eddy core with thermohaline anomalies that favour salt-finger type double diffusion.

nately we do not have a CTD profile in "Region 1 " in the eddy edge region. Calculating $R i$ from the station further away from the eddy core (at about $-40 \mathrm{~km}$ ), no critical $R i$ are found (Fig. 4h). However, superinertial waves originating from the core should also reflect and/or dissipate here. Joyce et al. (2013) also derive NIW energy accumulation and a critical layer at the edge of an ACE (Gulf Stream warm core ring) at its mixed layer base. Kroll (1993) found instability at the eddy edge region and expect an erosion of the eddy from a theoretical model.

Across the whole extent of the eddy, but below the low oxygen core, we observe velocity finestructure to align with salt-finger type double diffusion critical $\left(\mathrm{Tu}\right.$ close to $\left.90^{\circ}\right)$ thermohaline finestructure. St. Laurent and Schmitt (1999) reported on an enhancement of mixing efficiency from the interaction between velocity shear and salt-finger type thermohaline anomalies.

A NIW and shear-induced erosion of the core create an upward flux of nutrients (and other substances from the core) which is supported by the $\mathrm{NO}_{3}^{-}$observations. Once $\mathrm{NO}_{3}^{-}$ is in the mixed layer the eddy retention (D'Ovidio et al., 2013; Condie and Condie, 2016) will trap a fraction of the upwelling waters. The AOU : $\mathrm{NO}_{3}^{-}$ratio of the eddy core is altered high (16) when compared with the classical Redfield ratio (8.625) or the background ratio (8.1). We estimated the $\mathrm{NO}_{3}^{-}$deficit for the eddy, which is about $1: 20$ when refer- enced to the total $\mathrm{NO}_{3}^{-}$content. Denitrification is one possible process, but the significant nitrate loss of the core seems too large to be explained by denitrification, given the minimal oxygen concentrations are as low as $3 \mu \mathrm{mol} \mathrm{kg}{ }^{-1}$.

We consider it more likely that a local recycling of nitrogen but not oxygen takes place, driven by a combination of eddy dynamics and gravitational sinking. The $\mathrm{NO}_{3}^{-}$eroded from the core enters the mixed layer and is incorporated into new production in the eddy euphotic layer. The nitrogen will then reenter the core via gravitational sinking of PON. Such an isolated core is the rarely observed case of an isolated volume of water in the open ocean and which allows one to study fundamental biogeochemical cycling processes in the absence of significant physical transport processes. A number of surprising biogeochemical cycling processes and ecosystem responses have been reported from the studies on eastern tropical North Atlantic low oxygen eddies (Löscher et al., 2015; Hauss et al., 2016; Fiedler et al., 2016; Fischer et al., 2016; Schütte et al., 2016b; Grundle et al., 2017).

It has to be mentioned that the erosion processes at the mixed layer base should also operate in cyclonic eddies and may explain the high productivity (and low oxygen cores) in the eastern tropical North Atlantic (see Karstensen et al., 2015). The primary energy source for the drivers of the mixing in the eddies, the NIWs, is the wind (e.g. D'Asaro, 1985), and therefore our upwelling concept (Fig. 8, right) can be 
interpreted as eddy-wind interaction. However, the underlying processes are not linked to Ekman transport divergence (e.g. as McGillicuddy et al., 2007) but to submesoscale dynamics, not routinely resolved by numerical models (Eden and Dietze, 2009). However, a parametrization is required as the oxygen decrease in the mesoscale eddies has been found to significantly impact the large scale - Schütte et al. (2016b) report an increase in oxygen reduction by as much as $7 \mu \mathrm{mol} \mathrm{kg}{ }^{-1}$ in the depth range of 50 to $150 \mathrm{~m}$ (peak reduction is $16 \mu \mathrm{mol} \mathrm{kg}{ }^{-1}$ at $100 \mathrm{~m}$ depth) in the eastern tropical Atlantic as a result of the high productivity in ACMEs.

Data availability. The glider (IFM12 and IFM13) and shipboard (R/V Meteor expedition M105) data used in this paper are freely available for download at doi:10.1594/PANGAEA.860781 (Karstensen et al., 2016).

Competing interests. The authors declare that they have no conflict of interest.

Acknowledgements. We thank the authorities of Cape Verde for the permission to work in their territorial waters. We acknowledge the support of the captains and crews of R/V Islandia (glider survey support) and R/V Meteor. We thank Tim Fischer for processing the M105 ADCP data as well as Marcus Dengler and Antony Bosse for fruitful discussions. The critical comments from two reviewers and the comments as well as support from the guest editor are very much appreciated. Financial support for this study was provided by a grant from Cluster of Excellence "The Future Ocean" to J. Karstensen, A. Körtzinger, C. R. Löscher, and H. Hauss. Glider data analysis was supported by the DFG Collaborative Research Centre 754 (http://www.sfb754.de). B. Fiedler was funded by German Ministry for Education and Research (BMBF) project SOPRAN (grant no. 03F0662A). F. Schütte and P. Testor were supported by the AWA trilateral project supported by BMBF (grant no. 01DG12073E). Analysis was supported by the European Union's Horizon 2020 research and innovation programme under grant agreement no. 633211 (AtlantOS).

Edited by: D. Gilbert

Reviewed by: two anonymous referees

\section{References}

Alford, M. H., MacKinnon, J. A., Simmons, H. L., and Nash, J. D.: Near-Inertial Internal Gravity Waves in the Ocean, Annu. Rev. Mar. Sci., 8, 95-123, 2016.

Armi, L. and Zenk, W.: Large lenses of highly saline Mediterranean water, J. Phys. Oceanogr., 14, 1560-1576, doi:10.1175/15200485(1987)017<1653:SEOTWO>2.0.CO;2, 1984.

Chelton, D. B., Schlax, M. G. and Samelson, R. M.: Global observations of nonlinear mesoscale eddies, Prog. Oceanogr., 91, 167-216, doi:10.1016/j.pocean.2011.01.002, 2011.
Condie, S. and Condie, R.: Retention of plankton within ocean eddies, Global Ecol. Biogeogr., 25, 1264-1277, doi:10.1111/geb.12485, 2016.

D'Asaro, E. A.: The energy flux from the wind to near-inertial motions in the mixed layer, J. Phys. Oceanogr., 15, 943-959, 1985.

D'Asaro, E. A.: Generation of submesoscale vorticies: a new mechanism, J. Geophys. Res., 93, 6685-6693, 1988.

Dewar, W. K. and Flierl, G. R.: Some Effects of the Wind on Rings, J. Phys. Oceanogr., 17, 1653-1667, doi:10.1175/15200485(1984)014<1560:LLOHSM>2.0.CO;2, 1987.

D’Ovidio, F., De Monte, S., Della Penna, A., Cotté, C., and Guinet, C.: Ecological implications of oceanic eddy retention in the open ocean: a Lagrangian approach, J. Phys. A, 46, 254023, doi:10.1088/1751-8113/46/25/254023, 2013.

Eden, C. and Dietze, H.: Effects of mesoscale eddy/wind interactions on biological new production and eddy kinetic energy, J. Geophys. Res., 114, C05023, doi:10.1029/2008JC005129, 2009.

Fiedler, B., Grundle, D. S., Schütte, F., Karstensen, J., Löscher, C. R., Hauss, H., Wagner, H., Loginova, A., Kiko, R., Silva, P., Tanhua, T., and Körtzinger, A.: Oxygen utilization and downward carbon flux in an oxygen-depleted eddy in the eastern tropical North Atlantic, Biogeosciences, 13, 5633-5647, doi:10.5194/bg13-5633-2016, 2016.

Fischer, G., Karstensen, J., Romero, O., Baumann, K.-H., Donner, B., Hefter, J., Mollenhauer, G., Iversen, M., Fiedler, B., Monteiro, I., and Körtzinger, A.: Bathypelagic particle flux signatures from a suboxic eddy in the oligotrophic tropical North Atlantic: production, sedimentation and preservation, Biogeosciences, 13, 3203-3223, doi:10.5194/bg-13-3203-2016, 2016.

Garcia, H. E. and Gordon, L. I.: Oxygen solubility in seawater: Better fitting equations, Limnol. Oceanogr., 37, 1307-1312, 1992.

Garcia, H. E. and Gordon, L. I.: Erratum: Oxygen solubility in seawater: better fitting equations, Limnol. Oceanogr., 38, 656, 1993.

Gregg, M. C., D'Asaro, E. A., Shay, T. J., and Larson, N.: Observations of Persistent Mixing and Near-Inertial Internal Waves, J. Phys. Oceanogr., 16, 856-885, doi:10.1175/15200485(1986)016<0856:OOPMAN>2.0.CO;2, 1986.

Grundle, D., Loescher, C., Krahmann, G., Altabet, M., Bange, H., Karstensen, J., Körtzinger, A., and Fiedler, B.: Low oxygen eddies in the eastern tropical North Atlantic: Implications for $\mathrm{N}_{2} \mathrm{O}$ cycling, Scientific reports, in review, 2017.

Hahn, J., Brandt, P., Greatbatch, R., Krahmann, G., and Körtzinger, A.: Oxygen variance and meridional oxygen supply in the Tropical North East Atlantic oxygen minimum zone, Clim. Dynam., 43, 2999-3024, 2014.

Halle, C. and Pinkel, R.: Internal wave variability in the Beaufort Sea during the winter of 1993/1994, J. Geophys. Res., 108, 3210 , doi:10.1029/2000JC000703, 2003.

Hauss, H., Christiansen, S., Schütte, F., Kiko, R., Edvam Lima, M., Rodrigues, E., Karstensen, J., Löscher, C. R., Körtzinger, A., and Fiedler, B.: Dead zone or oasis in the open ocean? Zooplankton distribution and migration in low-oxygen modewater eddies, Biogeosciences, 13, 1977-1989, doi:10.5194/bg-13-1977-2016, 2016.

Hua, B. L., Menesguen, C., Gentil, S. L., Schopp, R., Marsset, B., and Aiki, H.: Layering and turbulence surrounding an anticyclonic oceanic vortex: in situ observations and quasi-geostrophic numerical simulations, J. Fluid Mech., 731, 418-442, 2013. 
IOC, SCOR and IAPSO: The international thermodynamic equation of seawater - 2010: Calculation and use of thermodynamic properties, Intergovernmental Oceanographic Commission, Manuals and Guides No. 56, UNESCO (English), 196 pp., 2010.

Johnson, K. S., Coletti, L. J., Jannasch, H. W., Sakamoto, C. M., Swift, D., and Riser, S. C.: Long-term nitrate measurements in the ocean using the In Situ Ultraviolet Spectrophotometer: sensor integration into the Apex profiling float, J. Atmos. Ocean. Tech., 30, 1854-1866, 2013.

Joyce, T. M., Toole, J. M., Klein, P., and Thomas, L. N.: A near-inertial mode observed within a Gulf Stream warm-core ring, J. Geophys. Res.-Oceans, 118, 1797-1806, doi:10.1002/jgrc.20141, 2013.

Karstensen, J., Fiedler, B., Schütte, F., Brandt, P., Körtzinger, A., Fischer, G., Zantopp, R., Hahn, J., Visbeck, M., and Wallace, D.: Open ocean dead zones in the tropical North Atlantic Ocean, Biogeosciences, 12, 2597-2605, doi:10.5194/bg-12-2597-2015, 2015.

Karstensen, J., Schütte, F., Pietri, A., Krahmann, G., Fiedler, B., Grundle, D., Hauss, H., Körtzinger, A., Löscher, C., Testor, P., Vieira, N., and Visbeck, M.: Upwelling and isolation in oxygendepleted anticyclonic modewater eddies and implications for nitrate cycling, doi:10.1594/PANGAEA.860781, 2016.

Kawaguchi, Y., Nishino, S, Inoue, J., Maeno, K., Takeda, H., and Oshima, K.: Enhanced diapycnal mixing due to near-inertial internal waves propagating through an anticyclonic eddy in the ice-free Chukchi Plateau, J. Phys. Oceanogr., 46, 2457-2481, doi:10.1175/JPO-D-15-0150.1, 2016.

Kostianoy, A. and Belkin, I.: A survey of observations on intrathermocline eddies in the world ocean, in: Mesoscale/Synoptic Coherent Structures in Geophysical Turbulence, edited by: Nihoul, J. and Jamart, B., Vol. 50, 821-841, Elsevier, New York, 1989.

Koszalka, I., Ceballos, L., and Bracco, A.: Vertical mixing and coherent anticyclones in the ocean: the role of stratification, Nonlin. Processes Geophys., 17, 37-47, doi:10.5194/npg-17-37-2010, 2010.

Krahmann, G., Brandt, P., Klaeschen, D., and Reston, T.: Middepth internal wave energy off the Iberian Peninsula estimated from seismic reflection data, J. Geophys. Res., 113, C12016, doi:10.1029/2007JC004678, 2008.

Kroll, J.: The stability of an axially symmetric warm-core model eddy on a stratified ocean, J. Mar. Res., 51, 273-292, 1993.

Kunze, E. and Sanford, T. B.: Observations of near-inertial waves in a front, J. Phys. Oceanogr., 14, 566-581, 1984.

Kunze, E.: Near-inertial wave propagation in geostrophic shear, J. Phys. Oceanogr., 15, 544-565, 1985.

Kunze, E., Schmidt, R. W., and Toole, J. M.: The energy balance in a warm core ring's near-inertial critical layer, J. Phys. Oceanogr., 25, 942-957, 1995.

Leaman, K. and Sanford, T.: Vertical energy propagation of inertial waves: A vector spectral analysis of velocity profiles, J. Geophys. Res., 80, 1975-1978, 1975.

Ledwell, J. R., McGillicuddy Jr., D. J., and Anderson, L. A.: Nutrient flux into an intense deep chlorophyll layer in a mode-water eddy, Deep-Sea Res., 55, 1139-1160, 2008.

Lee, D. and Niiler, P.: The inertial chimney: The near-inertial energy drainage from the ocean surface to the deep layer, J. Geophys. Res., 103, 7579-7591, 1998.
Lévy, M., Ferrari, R., Franks, P. J. S., Martin, A. P., and Rivière, P.: Bringing physics to life at the submesoscale, Geophys. Res. Lett., 39, L14602, doi:10.1029/2012GL052756, 2012.

Löscher, C. R., Fischer, M. A., Neulinger, S. C., Fiedler, B., Philippi, M., Schütte, F., Singh, A., Hauss, H., Karstensen, J., Körtzinger, A., Künzel, S., and Schmitz, R. A.: Hidden biosphere in an oxygen-deficient Atlantic open-ocean eddy: future implications of ocean deoxygenation on primary production in the eastern tropical North Atlantic, Biogeosciences, 12, 7467-7482, doi:10.5194/bg-12-7467-2015, 2015.

Mahadevan, A., Thomas, L. N., and Tandon, A.: Comment on "Eddy/Wind Interactions Stimulate Extraordinary Mid-Ocean Plankton Blooms", Science, 320, 448, doi:10.1126/science.1152111, 2008.

McDougall, T. J. and Barker, P. M.: Getting started with TEOS-10 and the Gibbs Seawater (GSW) Oceanographic Toolbox, 28 pp., SCOR/IAPSO WG127, 2011.

McDougall, T. J., Jackett, D. R., Millero, F. J., Pawlowicz, R., and Barker, P. M.: A global algorithm for estimating Absolute Salinity, Ocean Sci., 8, 1123-1134, doi:10.5194/os-8-11232012, 2012.

McGillicuddy, D. J., Anderson, L. A., Bates, N. R., Bibby, T., Buesseler, K. O., Carlson, C. A., Davis, C. S., Ewart, C., Falkowski, P. G., Goldthwait, S. A., Hansell, D. A., Jenkins, W. J., Johnson, R., Kosnyrev, V. K., Ledwell, J. R., Li, Q. P., Siegel, D. A., and Steinberg, D. K.: Eddy/Wind Interactions Stimulate Extraordinary Mid-Ocean Plankton Blooms, Science, 316, 1021-1026, doi:10.1126/science.1136256, 2007.

McWilliams, J. C.: Submesoscale, coherent vortices in the ocean, Rev. Geophys., 23, 165-182, doi:10.1029/RG023i002p00165, 1985.

McWilliams, J. C.: Submesoscale currents in the ocean, P. R. Soc. A, 472, 20160117, doi:10.1098/rspa.2016.0117, 2016.

Redfield, A. C., Ketchum, B. H., and Richards, F. A.: The influence of organisms on the composition of seawater, in: The Sea, Interscience, edited by: Hill, M. N., 26-77, 1963.

Sakamoto, C. M., Johnson, K. S., and Coletti, L. J.: An improved algorithm for the computation of nitrate concentrations in seawater using an in situ ultraviolet spectrophotometer, Limnol. Oceanogr.-Meth., 7, 132-143, 2009.

Schütte, F., Brandt, P., and Karstensen, J.: Occurrence and characteristics of mesoscale eddies in the tropical northeastern Atlantic Ocean, Ocean Sci., 12, 663-685, doi:10.5194/os-12-663-2016, 2016a.

Schütte, F., Karstensen, J., Krahmann, G., Hauss, H., Fiedler, B., Brandt, P., Visbeck, M., and Körtzinger, A.: Characterization of "dead-zone" eddies in the eastern tropical North Atlantic, Biogeosciences, 13, 5865-5881, doi:10.5194/bg-13-5865-2016, $2016 b$.

Sheen, K. L., Brearley, J. A., Naveira Garabato, A. C., Smeed, D. A., St Laurent, L., Meredith, M. P., Thurnherr, A. M., and Waterman, S. N.: Modification of turbulent dissipation rates by a deep Southern Ocean eddy, Geophys. Res. Lett., 42, 3450-3457, doi:10.1002/2015GL063216, 2015.

St. Laurent, L. and Schmitt, R. W.: The Contribution of Salt Fingers to Vertical Mixing in the North Atlantic Tracer Release Experiment, J. Phys. Oceanogr., 29, 1404-1424, doi:10.1175/15200485(1999)029<1404:TCOSFT>2.0.CO;2, 1999. 
Testor, P. and Gascard, J.-C.: Post-convection spreading phase in the Northwestern Mediterranean Sea, Deep-Sea Res. Pt. I, 53, 869-893, doi:10.1016/j.dsr.2006.02.004, 2006.

Thomas, L. N.: Formation of intrathermocline eddies at ocean fronts by wind-driven destruction of potential vorticity, Dynam. Atmos. Oceans, 45, 252-273, 2008.

Whitt, D. B. and Thomas, L. N.: Near-inertial waves in strongly baroclinic currents, J. Phys. Oceanogr., 43, 706-725, doi:10.1175/JPO-D-12-0132.1, 2013.

Whitt, D. B., Thomas, L. N., Arrigo, K. R., and Fringer, O. B.: Near-inertial waves in oceanic fronts: from generation to dissipation, available at: http://purl.stanford.edu/ct242wb1020 (last access: 25 April 2017), 2014.
Zhang, Z., Zhang, Y., Wang, W., and Huang, R. X.: Universal structure of mesoscale eddies in the ocean, Geophys. Res. Lett., 40, 3677-3681, 2013.

Zhang, Z., Zhang, Y., and Wang, W.: Three-compartment structure of subsurface-intensified mesoscale eddies in the ocean, J. Geophys. Res.-Oceans, 122, 1653-1664, doi:10.1002/2016JC012376, 2017. 